\title{
Equatorial plasma bubble seeding by MSTIDs in the ionosphere
}

\author{
Hisao Takahashi ${ }^{1 *}$ (D, Cristiano Max Wrasse ${ }^{1}$, Cosme Alexandre Oliveira Barros Figueiredo ${ }^{1}$, Diego Barros ${ }^{1}$, \\ Mangalathayil Ali Abdu', Yuichi Otsuka² and Kazuo Shiokawa²
}

\begin{abstract}
Occurrences of equatorial plasma bubbles (EPBs) and medium-scale traveling ionospheric disturbances (MSTIDs) were studied using GPS satellite data-based total electron content mapping, ionograms, and $630 \mathrm{~nm}$ all-sky airglow images observed over the South American continent during the period of 2014-2015. In many cases, we observed a close relationship between the inter-bubble distance and the horizontal wavelength of the MSTIDs. The MSTIDs followed by EPBs occurred primarily in the afternoon to evening period under strong tropospheric convective activities (cold fronts and/or intertropical convergence zones). The close relationship between EPBs and MSTIDs suggests that MSTIDs could be one of the seeding sources of EPBs.
\end{abstract}

Keywords: Equatorial plasma bubbles, MSTID, Gravity waves

\section{Introduction}

Equatorial plasma bubbles (EPBs) are a consequence of the development of equatorial ionospheric irregularities under the condition of the Rayleigh-Taylor instability (RTI). During the evening, the passage of the solar terminator produces F-layer uplifting driven by the pre-reversal enhancement of the electric field (PRE). The upward drift velocity and the F-layer altitude make the RTI conditions favorable for the development of EPBs (Abdu 2005; Kelley 2009).

In addition to the RTI condition, there must be a seeding process that kicks the F-layer bottom side to initiate perturbations. Many previous studies have highlighted possible seeding processes, such as contributions of atmospheric gravity waves in the ionosphere (Rottger 1973; Singh et al. 1997), the passage of the solar terminator (Tulasi Ram et al. 2014), and medium-scale traveling ionospheric disturbances (MSTIDs) (Taori et al. 2015). Tsunoda et al. (2011) pointed out the presence of large-scale wave structures (LSWSs) along the magnetic equator on the afternoon to evening side. Vertical oscillations of the longitudinal waves increase toward the evening side and may accelerate F-layer uplifting,

\footnotetext{
* Correspondence: hisao.takahashi@inpe.br

${ }^{1}$ Instituto Nacional de Pesquisas Espaciais, INPE, São José dos Campos, SP, Brazil

Full list of author information is available at the end of the article
}

resulting in the generation of EPBs (Abdu et al. 2015). On the other hand, Kudeki et al. (2007) presented the importance of eastward thermospheric winds during the sunset period (the sunset vortex) for the generation of F-layer instabilities and EPB seeding.

For the RTI condition scenario, the development and physical characteristics of EPBs have been extensively studied and discussed and there exists some common knowledge (e.g., Abdu 2001). However, regarding RTI seeding processes, discussions concerning the dynamical processes are still open. Rottger (1973) reported a quasi-periodic spread $\mathrm{F}$ structure in the west-east extension, which could be explained by atmospheric gravity waves propagating in the thermosphere. Singh et al. (1997) reported a possible mechanism for the periodic ion density perturbation caused by gravity waves, which then develop into plasma bubbles. Most recently, Abdu et al. (2015) discussed atmospheric gravity waves in the ionosphere as a potential source to excite plasma bubbles.

Medium-scale traveling ionospheric disturbances (MSTIDs) are plasma density perturbations propagating in the ionosphere. They have been classified into two groups (Otsuka et al. 2013). The first group is generated via electrodynamical forces under the condition of the Perkins instability (Perkins 1973) during the evening to nighttime. This group is primarily observed in middle 
latitudes, and their propagation direction is primarily southwest in the northern hemisphere and northwest in the southern hemisphere (Otsuka et al. 2004; Shiokawa et al. 2005; Duly et al. 2013), even though it depends on the background thermospheric winds. These MSTIDs are characterized by a period of $15-60 \mathrm{~min}$, a horizontal wavelength of $100-1000 \mathrm{~km}$, and a phase speed of 100 $300 \mathrm{~m} / \mathrm{s}$ (Hunsucker 1982). The second group is generated via atmospheric gravity waves propagating in the F-layer bottom height (Otsuka et al. 2013). The propagation direction depends on the gravity wave source region and the background winds in the lower atmosphere. Fukushima et al. (2012) reported that most MSTID events observed in the equatorial and low latitude regions were related to tropospheric convection. Paulino et al. (2016) observed nighttime wave propagation in the $630 \mathrm{~nm}$ emission layer and reported that these MSTIDs have different characteristics compared to those originating from the Perkins instability in the ionosphere, suggesting the presence of gravity wave propagation in the thermosphere. Further, their recent work (Paulino et al. 2018) reinforced the propagation of gravity waves in the thermosphere from below via measurements of the intrinsic wave parameters.

MSTIDs as a possible candidate to generate plasma bubbles have been discussed by several groups. Krall et al. (2011) simulated plasma bubble seeding using the effect of MSTIDs during the post-sunset hours. Taori

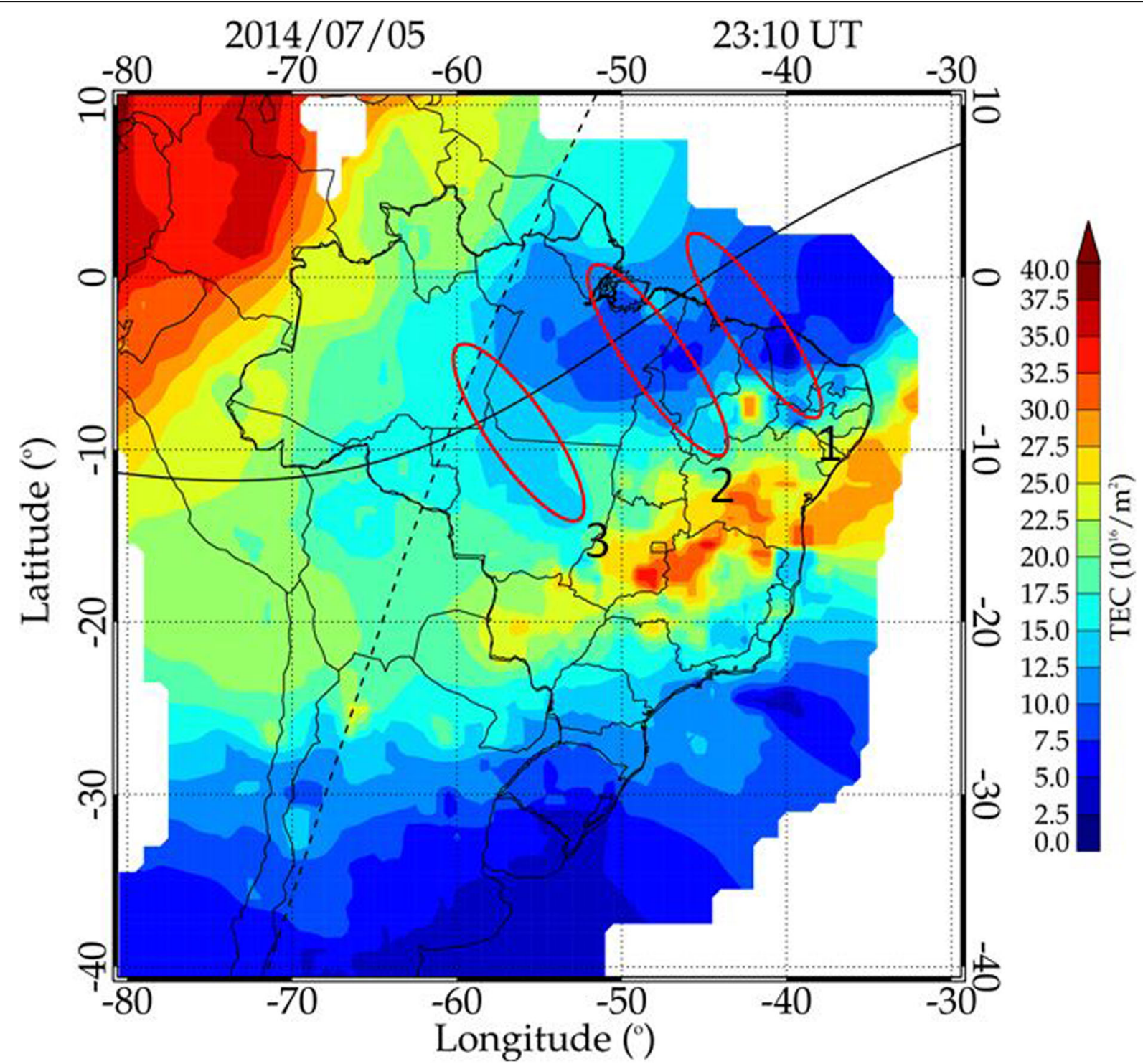

Fig. 1 TECMap over South America on the evening of July 05, 2014, at 23:10 UT. The black line indicates the geomagnetic equator, and the broken line indicates the solar terminator line at an altitude of $300 \mathrm{~km}$. The color shade scale is from TEC unit 01 (dark blue) to 40 (dark red). The red-lined elliptical circles depict the location and extension of the EPBs 
et al. (2015) observed EPBs and MSTIDs simultaneously in the Indian sector and argued that the observed MSTIDs could be one of the seeding processes. Observational evidence of EPB seeding by MSTIDs is, however, rare. The conditions and types of MSTIDs effective in seeding EPBs are still not well known.

A close relationship between the inter-bubble distances (measured via $630 \mathrm{~nm}$ airglow images) and the horizontal wavelength of the mesospheric gravity waves (MGWs) (measured via $\mathrm{OH}$ images) has been discussed by Takahashi et al. (2009) and Paulino et al. (2011). They argue that the gravity waves in the upper mesosphere $(\sim 90 \mathrm{~km})$ may propagate up to the lower thermosphere modulating the F-layer bottom height and generating EPBs. Makela et al. (2010) observed the periodic spacing of EPBs via a $630 \mathrm{~nm}$ imager at Cerro Tololo $\left(30.2^{\circ} \mathrm{S}, 70.8^{\circ} \mathrm{W}\right)$ and mentioned

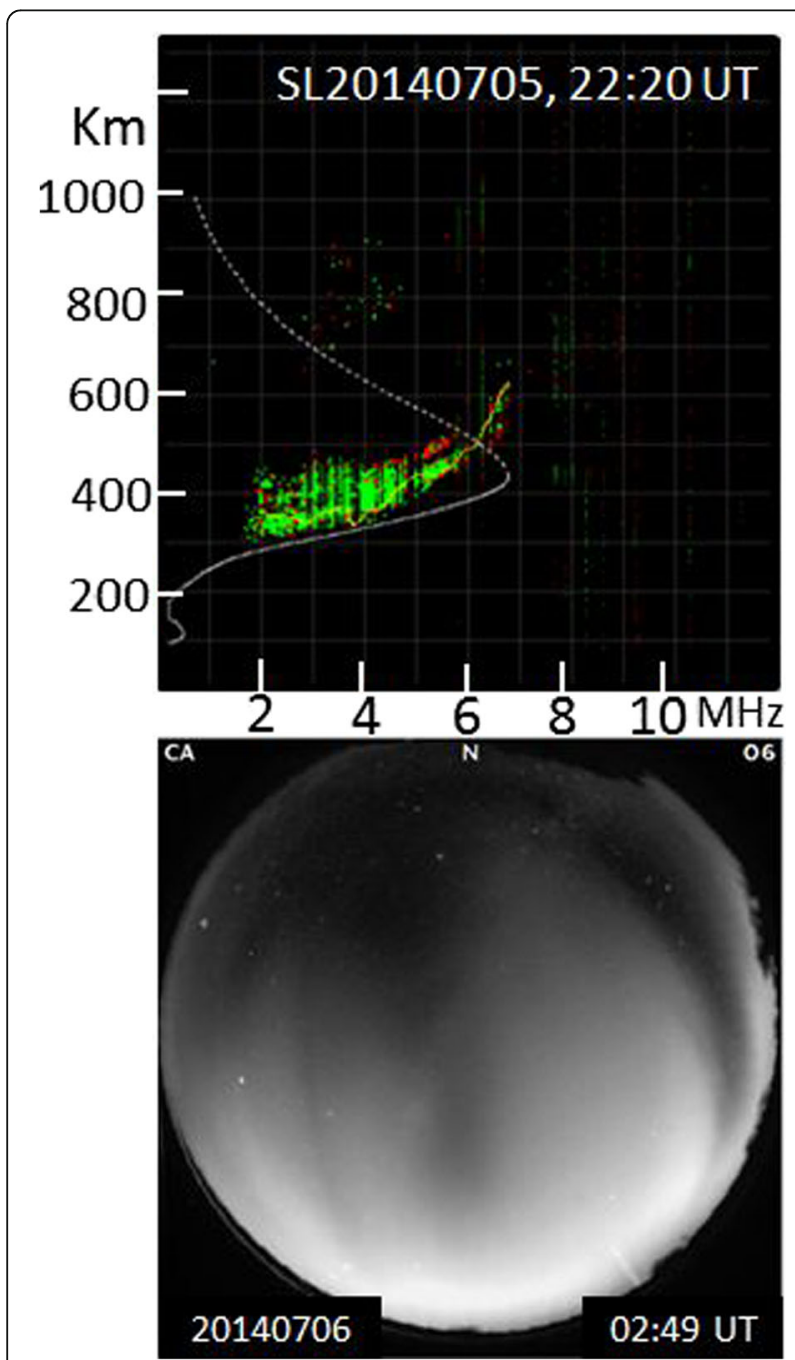

Fig. 2 Signature of the equatorial plasma bubbles observed by the ionogram (upper panel) at São Luis $\left(2.6^{\circ} \mathrm{S}, 44.2^{\circ} \mathrm{W}\right)$ at 22:20 UT and the $630 \mathrm{~nm}$ airglow image (lower panel) observed at Cariri $\left(7.4^{\circ} \mathrm{S}\right.$, $\left.36.5^{\circ} \mathrm{W}\right)$ at $02: 49 \mathrm{UT}(23: 49 \mathrm{LT})$ on July $05-06,2014$ that the spacing could be related to the horizontal wavelength of the MGWs. Therefore, our present interest is to explore the relationship between the inter-bubble distances and MSTIDs in the ionosphere.

In the present study, we analyze EPB seeding and development under the propagation of MSTIDs. The initial phase of EPB development was detected by monitoring total electron content (TEC) maps (depletions of TEC larger than $20 \%$ of the ambient TEC field). MSTIDs were identified via small-scale perturbations (amplitudes of less than 0.5 TEC units) with wavelike structures with propagation modes. From the same day presence of MSTIDs during the afternoon to evening and EPBs in the evening to night period, we analyzed their characteristics to determine common factors, such as horizontal
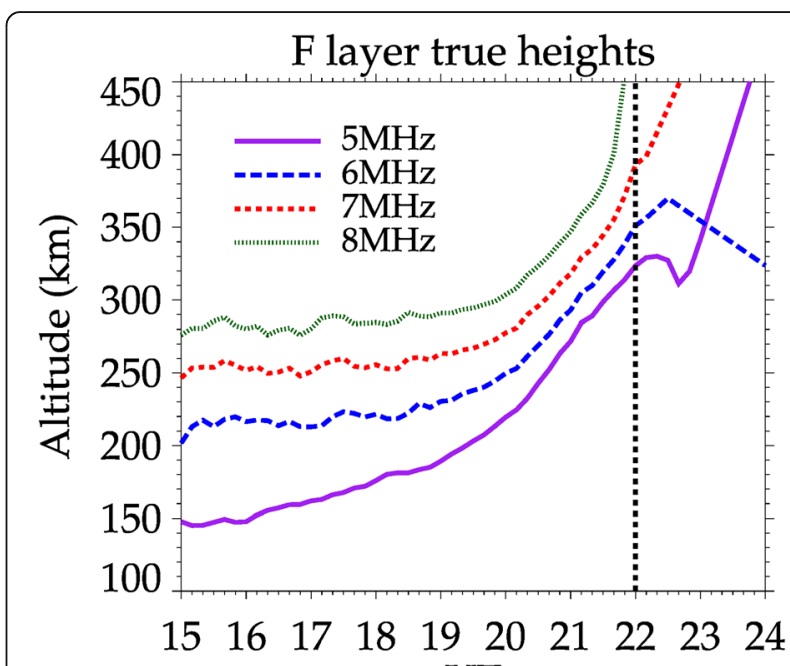

UT

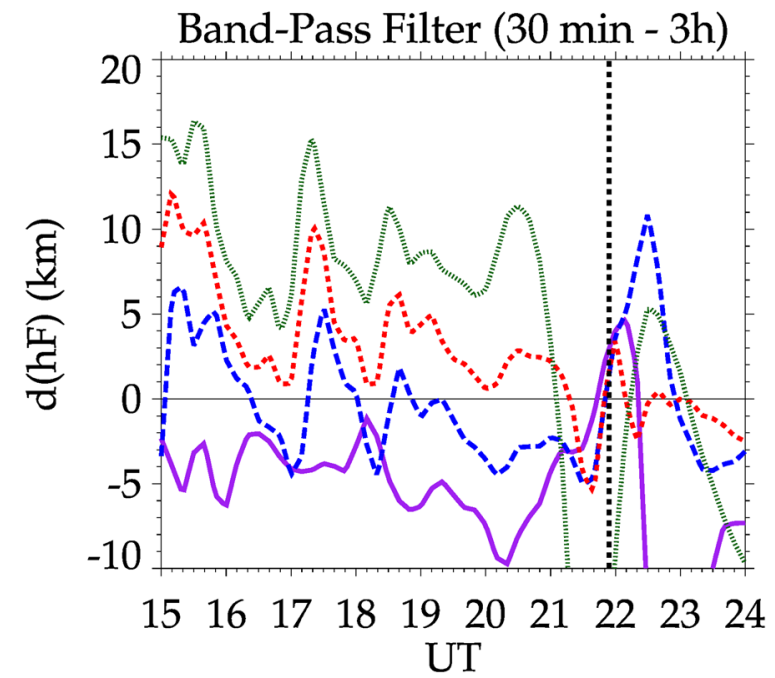

Fig. 3 Temporal variations in the fixed frequency $(5-8 \mathrm{MHz})$ true heights, hF (upper), and deviation of hF (band-pass filtered (30 min-3 h) (lower) observed at São Luis in the afternoon to evening period on July 05, 2014. The vertical dotted line indicates the solar terminator at an altitude of $300 \mathrm{~km}$ 
wavelengths and inter-bubble distances. Two case studies and statistical analyses are presented.

\section{Methods/Experimental}

In the present study, we used TEC map (TECMap) data obtained by EMBRACE (Brazilian Studies and Monitoring of Space Weather (http://www2.inpe.br/climaespacial/). TECMap covers an area of $30-70^{\circ} \mathrm{W}$ and $10^{\circ} \mathrm{N}-35^{\circ} \mathrm{S}$ with a temporal resolution of $10 \mathrm{~min}$. The spatial resolution of the map depends on the density of the ground-based GPS receivers. Spatial resolutions of 50$100 \mathrm{~km}$ at low to middle latitudes $\left(15-35^{\circ} \mathrm{S}\right)$ and larger than $100 \mathrm{~km}$ in the equatorial region $\left(10^{\circ} \mathrm{S}-10^{\circ} \mathrm{N}\right)$ were obtained. The TECMaps and ground-based Global Navigation Satellite System (GNSS) receiver network used in this study have been reported elsewhere (Takahashi et al. 2016).

The temporal variation in the TEC (dTEC) was obtained from the line-of-sight TEC (STEC) by calculating the short-term variation (dSTEC) from $1 \mathrm{~h}$ running means and then transforming it to vertical TEC (VTEC). The dTEC map was obtained by plotting the dTEC at the ionospheric pierce point at an altitude of $300 \mathrm{~km}$ after smoothing it out in space and time. The process of dTEC mapping has been reported by Figueiredo et al. (2017). Because the ground GPS receivers in the $0-15^{\circ} \mathrm{S}$ region are less dense compared to those in the $15-30^{\circ} \mathrm{S}$ region, the dTEC map was made in two different spatial resolutions: approximately $100 \mathrm{~km}$ for the former region and $50 \mathrm{~km}$ for the latter region. We classified the spatial and temporal variations of dTEC as an MSTID if (1) the amplitude of the oscillation was larger than 0.2 TEC units (TECu) and (2) the wave crest extended longer than $500 \mathrm{~km}$ followed by a wave valley and there were at least two propagating wave crests. These criteria are similar to those presented by Otsuka et al. (2013). The threshold level of 0.2 TECu was chosen because most of the wave structures were identified with amplitudes larger than that. The dTEC noise level was less than 0.1 $\mathrm{TECu}$. The calculation process has been reported by Figueiredo et al. (2017). To visualize the perturbation in space and time, $\mathrm{N}-\mathrm{S}$ - and $\mathrm{E}-\mathrm{W}$-sliced dTECs with $0.5^{\circ}$ steps were plotted as a function of time (on a keogram). The wave characteristics, i.e., the horizontal wavelength, phase velocity, and direction of propagation, were calculated from this visualization (Figueiredo et al. 2018).

The F-layer bottom height variability and vertical uplifting during the afternoon to the terminator passing period were monitored via two ionosondes: one located at São Luis $\left(2.6^{\circ} \mathrm{S}, 44.2^{\circ} \mathrm{W}\right)$ and the other located at Fortaleza $\left(3.9^{\circ} \mathrm{S}, 38.4^{\circ} \mathrm{W}\right)$. In the present study, the F-layer true height $(\mathrm{hF})$ at fixed plasma frequencies $(5,6$, 7 , and $8 \mathrm{MHz}$ ) was used. The data sampling interval was $10 \mathrm{~min}$, which makes it difficult to pick up temporal oscillations shorter than $30 \mathrm{~min}$. In order to see short-period oscillations $(0.5-3 \mathrm{~h})$ in the temporal variation of $\mathrm{hF}, \mathrm{d}(\mathrm{hF})$ was calculated using a band-pass filter that could eliminate longer period oscillations. In
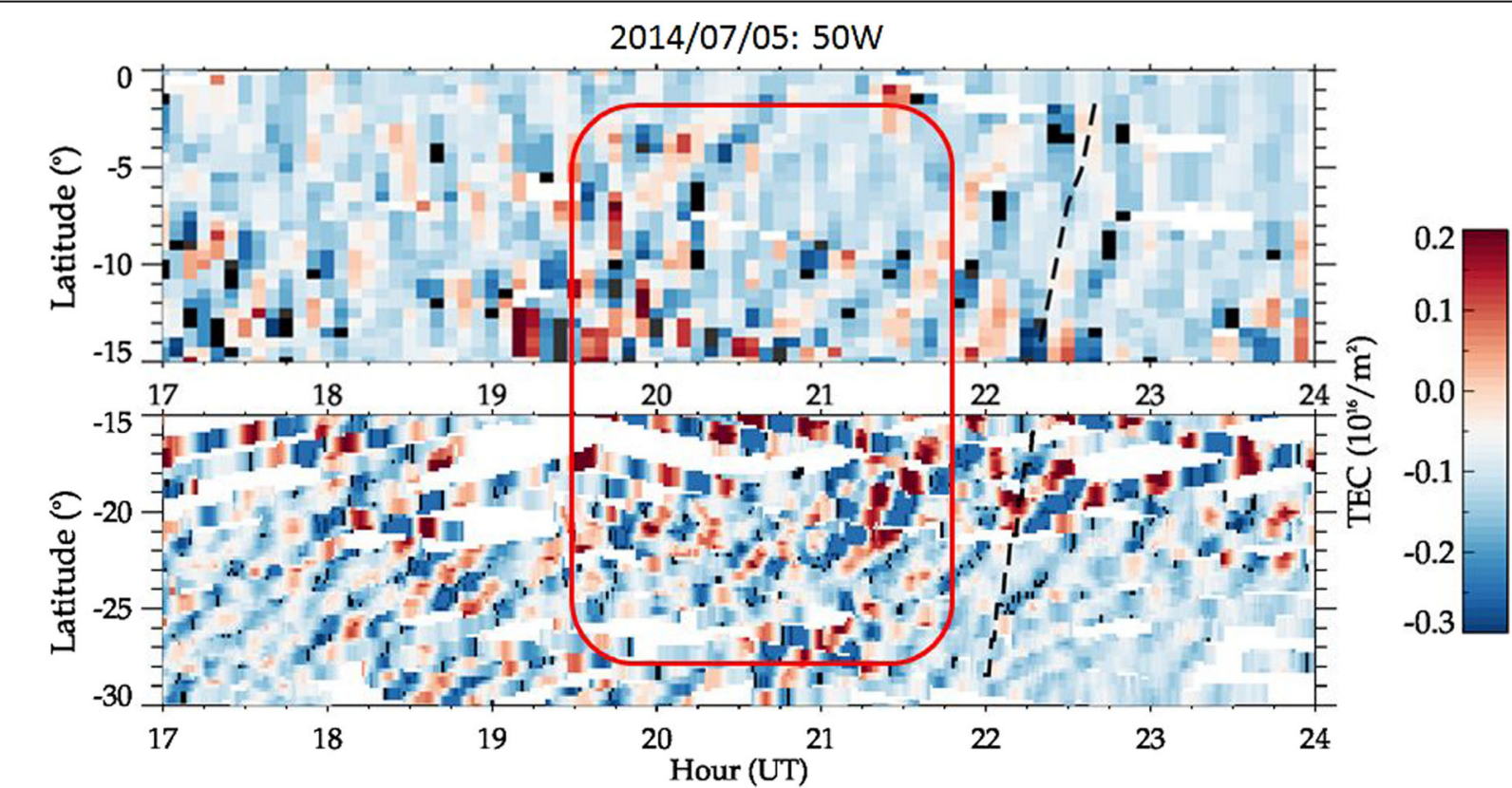

Fig. 4 Keogram of a dTEC map: latitudinal cuts of $0-15^{\circ} \mathrm{S}$ (upper) and 15-30 $\mathrm{S}$ (lower) at $50^{\circ} \mathrm{W}$ as a function of time from 17:00 UT (14:00 LT) to 24:00 UT (21:00 LT) in the afternoon to evening period on July 05, 2014. The red-lined box indicates where the MSTIDs are propagating from S to $\mathrm{N}$. The black broken lines indicate the solar terminator at an latitude of $300 \mathrm{~km}$ 
addition to the ionograms, all-sky airglow images of the $630 \mathrm{~nm}$ and $\mathrm{OH}$ emissions were used to monitor the plasma bubbles and mesospheric gravity waves, respectively. Details concerning the imager and data reduction have been reported elsewhere (Takahashi et al. 2015).

\section{Results}

\section{Case study 1: July 05, 2014}

Figure 1 shows a TECMap over South America on the evening of July 05,2014 . The universal time (UT) of $23: 10$ corresponds to a local time (LT) of $20: 10$ at $45^{\circ} \mathrm{W}$. The broken line indicates the solar terminator crossing the F layer at $300 \mathrm{~km}$ altitude, after which the ionization production ceased. One can easily recognize that, along the geomagnetic equator line, TEC depletion extended from $35^{\circ} \mathrm{W}$ to $55^{\circ} \mathrm{W}$. This is the trough of the post-sunset equatorial ionization anomaly (PS-EIA), which is caused by F-layer plasma uplift due to an increase in the zonal electric field, known as PRE, during the sunset period. If the vertical drift velocity exceeds a certain level, the bottom side gradient region of the $\mathrm{F}$ layer becomes unstable under the RTI condition and starts to generate plasma irregularities. Note that the TECMap (Fig. 1) shows periodic TEC decreasing along the magnetic equator, some of which extended toward the southeast as highlighted by the elliptical circles numbered 1, 2, and 3. The depletions, however, did not extend up to the PS-EIA crest region. These periodic depletions appear to be an initial phase of the plasma bubbles that are developed along the geomagnetic field lines. The distance between depletions 1 and 2 is approximately $640 \pm 50 \mathrm{~km}$.

On this evening, both ionosondes at São Luís and Fortaleza registered satellite traces (at 21:50 UT) followed by spread F after 22:00 UT. In Fig. 2 (upper panel), the ionogram at São Luis at 22:20 UT (19:20 LT) is presented. The spread F continued up to 04:00 UT (01:00 LT). The $630 \mathrm{~nm}$ emission, observed by an all-sky imager at Cariri $\left(7.4^{\circ} \mathrm{S}, 36.5^{\circ} \mathrm{W}\right)$, also registered plasma bubbles, which are shown in Fig. 2 (lower panel) as a snapshot at 02:49 UT (23:49 LT). Due to the cloudy conditions on this evening, airglow images could not be taken in the beginning phase of the plasma bubble development (at around 22:00 UT). Using a sequence of images collected from 02:40 UT to 03:30 UT, a zonal drift velocity of $76 \mathrm{~m} / \mathrm{s}$ and an inter-depletion distance of $485 \mathrm{~km}$ were obtained. These are characteristic of plasma bubbles. The inter-bubble distance is, however, shorter than that measured by TECMap at 23:00 UT. Normally, the inter-bubble distances tend to decrease from the evening to the midnight time zones, as observed by Barros et al. (2018).

In order to investigate any dynamical forcing of the $\mathrm{F}$ layer prior to and during the terminator passage, temporal variations in the true height of the ionogram-fixed frequencies $(5,6,7$, and $8 \mathrm{MHz})$ observed at São Luis were plotted in Fig. 3 (upper panel). The vertical drift speed at around 21:00 UT was $16 \pm 2 \mathrm{~m} / \mathrm{s}$. Note that three frequencies $(6,7$, and $8 \mathrm{MHz})$ showed a common oscillation during the period of 15:00-20:00 UT. The $d(h F)$ was obtained using a band-pass filter $(0.5-3 \mathrm{~h})$ in order to eliminate long and large $\mathrm{hF}$ gradients during the evening period, which is shown in Fig. 3 (lower panel). One can see a periodic oscillation with a period of $\sim 70 \mathrm{~min}$ at around 18:00 UT with the phase propagating downward. This indicates that there was gravity wave propagation in the $\mathrm{F}$ layer during the afternoon sector (see also Abdu et al. 2009). Periodic oscillations shorter than $0.5 \mathrm{~h}$ cannot be seen in Fig. 3 (lower panel) due to the limitation of the data sampling interval (10 min) and the applied band-pass filtering, as mentioned above.

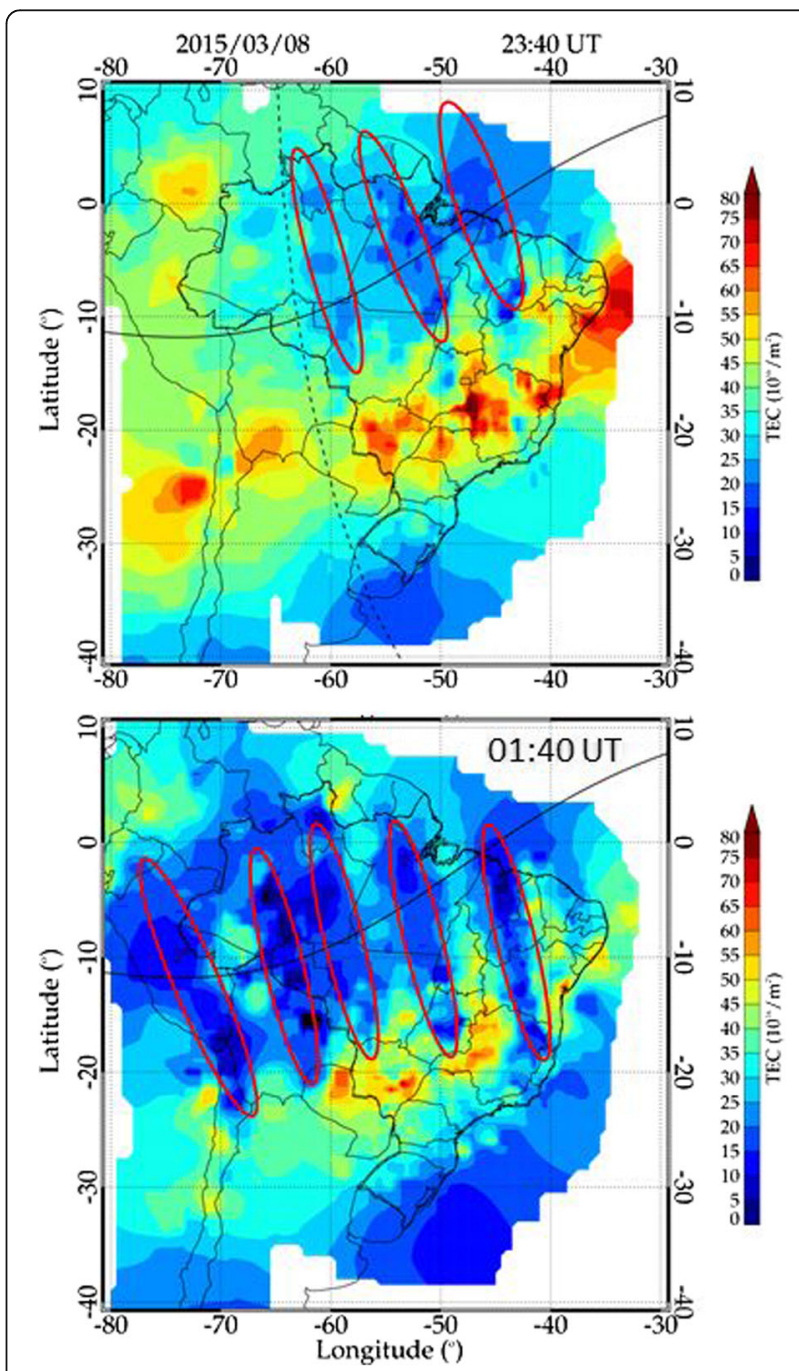

Fig. 5 TECMaps, same as Fig. 1 but on the evening of March 08, 2015. The inter-bubble distances at 23:40 UT were $\sim 770 \mathrm{~km}$ and at 01:40 UT were $\sim 650 \mathrm{~km}$ 
The oscillation of the F layer could also be seen in the dTEC maps. Figure 4 shows a keogram of dTEC, i.e., a latitudinally sliced $\left(0-30^{\circ} \mathrm{S}\right)$ dTEC map at $50^{\circ} \mathrm{W}$ as a function of time from 17:00 UT to 24:00 UT. Due to the different spatial and temporal resolutions (as mentioned in the previous section), the keogram is divided in two latitudinal zones, from 0 to $15^{\circ} \mathrm{S}$ with a temporal resolution of $5 \mathrm{~min}$ and from $15^{\circ} \mathrm{S}$ to $30^{\circ} \mathrm{S}$ with a temporal resolution of $1 \mathrm{~min}$. The broken line indicates the solar terminator at an altitude of $300 \mathrm{~km}$. During the period between 19:30 UT and 21:45 UT (highlighted by a box), one can see periodic perturbations of dTEC with a period of $\sim 30 \mathrm{~min}$ in both the $0-15^{\circ} \mathrm{S}$ and $15-30^{\circ} \mathrm{S}$ keograms. It is clear that the perturbations are propagating from the south $\left(\sim 22^{\circ} \mathrm{S}\right)$ to the north up to $\sim 5^{\circ} \mathrm{S}$. The keogram of the longitudinal $(\mathrm{E}-\mathrm{W})$ slice at $7^{\circ} \mathrm{S}$ (not presented here) did not show any clear propagation mode. In the $5-15^{\circ} \mathrm{S}$ region, therefore, it appears that there was a wave propagating northward. Due to the low spatial and temporal resolution of the $0-15^{\circ} \mathrm{S}$ keogram, we could not obtain wave parameters with sufficient accuracy in this region. Conversely, from the $15-30^{\circ} \mathrm{S}$ keograms (lower panel), which have better spatial and temporal resolutions, it was possible to obtain the wave characteristics from the time interval of 20:30 UT to 21:30 UT: the horizontal wavelength was $732 \pm 50 \mathrm{~km}$, the period was $26 \pm 5 \mathrm{~min}$, and the propagation direction was $3.5 \pm 5^{\circ}$ from the north. According to the classification of ionospheric perturbations, this event can be classified as an MSTID (Hunsucker 1982). The dTEC perturbations after 22:00 UT in the $15-20^{\circ} \mathrm{S}$ region are most likely the signature of the plasma bubbles seen in the ionogram.

It appears that the wave structure observed in the 0 $15^{\circ} \mathrm{S}$ region (upper panel) is similar to those observed in the $15-30^{\circ} \mathrm{S}$ region (lower panel). The MSTID observed by the ionogram (Fig. 3) and the dTEC keogram (Fig. 4) suggests that these waves perturbed the F-layer bottom height from 19:30 UT to 21:40 UT and generated plasma bubbles at around 22:00 UT. The observed horizontal wavelength of the MSTID was $\sim 730 \mathrm{~km}$, and the inter-bubble distance was approximately $640 \mathrm{~km}$. Note that the occurrence of EPBs during the months of JuneJuly in this longitudinal zone is rare (Nishioka et al. 2008).

\section{Case study 2: March 08, 2015}

Figure 5 presents TECMaps on the evening of March 08, 2015. The upper panel (at 23:40 UT) shows three consecutive bubbles (elliptic circles) behind the solar terminator (dotted line). These bubbles are newly formed and in the developing phase. The inter-bubble distance between bubbles 1 and 2 is approximately $770 \mathrm{~km}$ along the geomagnetic equator. Two hours later at 01:40 UT (lower panel), five well-developed bubbles can be seen. Note that they are separated by approximately $640 \mathrm{~km}$, which is a smaller distance than those observed at 22:40 UT. Such periodic structures of EPBs have been frequently observed over South America (Takahashi et al. 2016). There have been discussions concerning the periodic structure of EPBs (e.g., Rottger 1973; Huang et al. 2013). Tsunoda et al. (2011) proposed the occurrence of

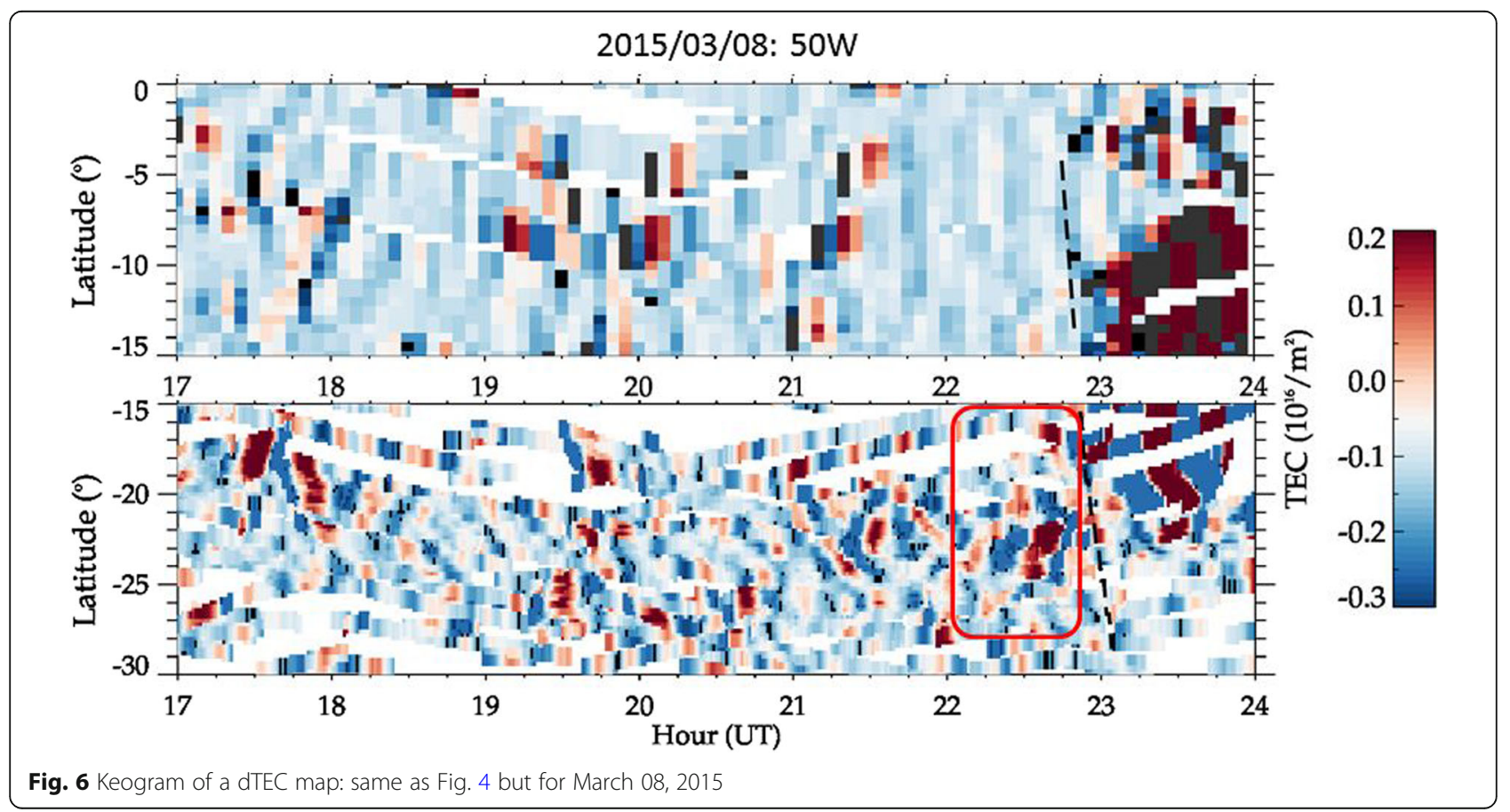


a large-scale wave structure (LSWS) along the geomagnetic equator.

In order to investigate possible periodic disturbances in the F-layer bottom heights, dTEC keograms are shown in Fig. 6. From the upper panel $\left(0-15^{\circ} \mathrm{S}\right)$, one can see three groups of dTEC perturbations with amplitudes of \pm 0.2 TECu. The first perturbation occurred at 18:00 UT propagating equatorward. The second perturbations occurred at around 19:30-20:10 UT and do not show a clear propagation mode but rather a local oscillation at $\sim 5-10^{\circ} \mathrm{S}$. The third perturbation occurred at 21:10 UT propagating equatorward. Due to the low temporal and spatial resolution of dTEC map, it was not possible to obtain the wave characteristics from the keogram.

On the other hand, the keogram of the $15-30^{\circ} \mathrm{S}$ regions (lower panel) did show several wave structures from 17:30 UT to 23:00 UT. Note that there are southward propagating waves at around 17:50 UT, 19:50 UT, and 21:10 UT. It appears that these waves started from low latitudes $\left(5-7^{\circ}\right.$ $\mathrm{S})$. However, there is another wave structure at 22:0023:00 UT (highlighted by a box) starting from $\sim 25^{\circ} \mathrm{S}$ with a perturbation amplitude of $\sim 0.3 \mathrm{TECu}$. It propagated north and intersected with the solar terminator at $300 \mathrm{~km}$ (broken line). We calculated its wave characteristics: a period of $22 \mathrm{~min}$, a horizontal wavelength of $760 \pm 50 \mathrm{~km}$, a phase speed of $570 \mathrm{~m} / \mathrm{s}$, and a direction of propagation of $32^{\circ}$ from the north. These are typical characteristics of an MSTID. Note that the horizontal wavelength is very close to the inter-bubble distance $(770 \mathrm{~km})$ observed at 23:40 UT soon after the terminator passed.

The ionogram at Fortaleza registered satellite traces starting at $\sim 22: 10 \mathrm{UT}$, and the spread F started at 23:00 UT. Figure 7 shows temporal variations in the true heights of the $5,6,7$, and $8 \mathrm{MHz}$ radio waves and $\mathrm{d}(\mathrm{hF})$. One can see that there are two distinct oscillation forms at around 18:00 UT and 19:30 UT, these are coincident with the dTEC keogram in Fig. 6 (upper panel). Conversely, the wave structure observed at 22:00-23:00 UT in the dTEC keogram (Fig. 6, lower panel) cannot be seen in the $d(h F)$ oscillation. This might be due to the overlap of the strong evening F-layer uplifting. This observational evidence suggests that the plasma bubbles 1 , 2 , and 3 in Fig. 5, with an inter-bubble distance of $770 \mathrm{~km}$, are closely related to the F-layer perturbation generated by the MSTID at around 22:00-23:00 UT, which might have crossed the solar terminator at a longitude of $45-50^{\circ} \mathrm{W}$.

\section{Discussion}

\section{EPB seeding by MSTIDs}

The two case studies presented above suggest that there is a relationship between the inter-bubble distances and the horizontal wavelengths of MSTIDs. It also suggests that the correlation between the EPB seeding and the

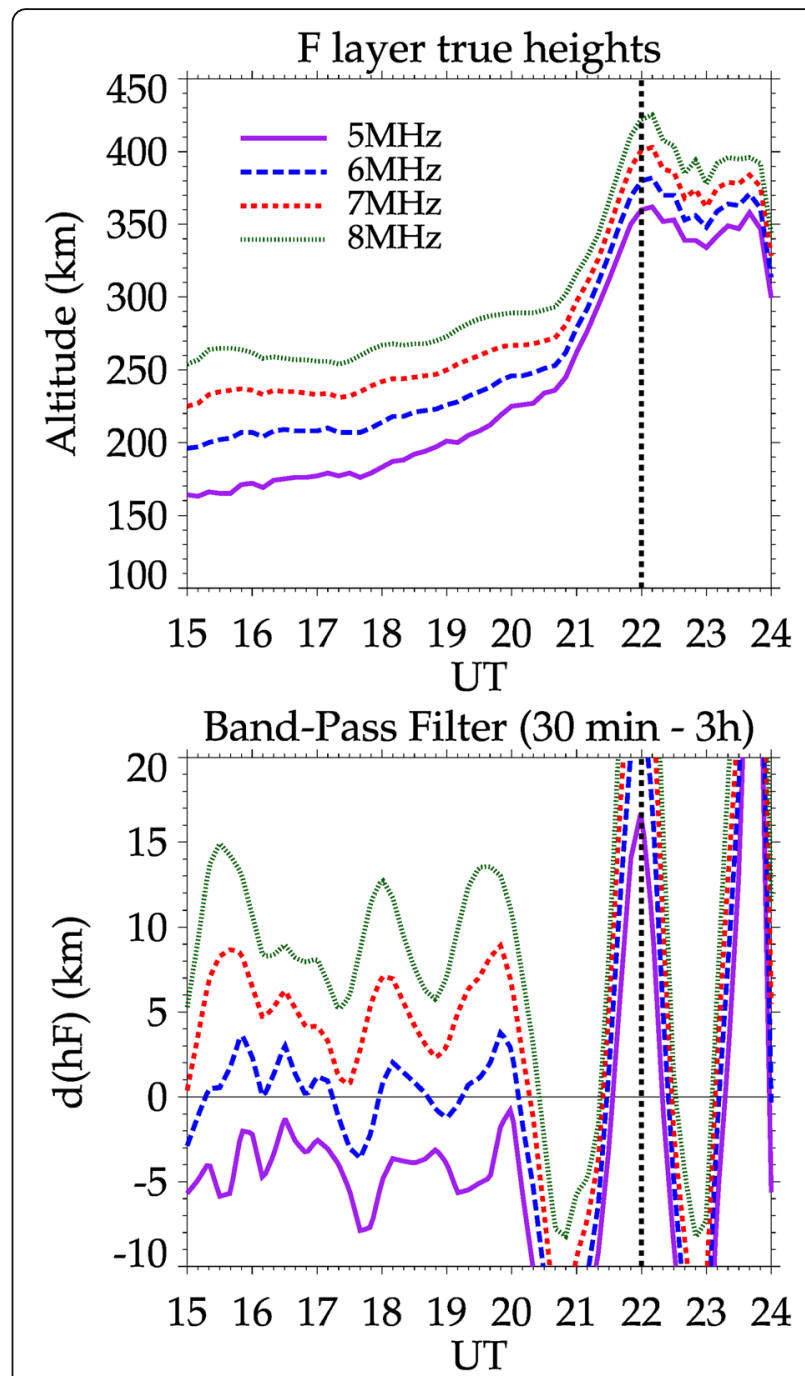

Fig. 7 Temporal variations in the fixed frequency $(5-8 \mathrm{MHz})$ true heights: same as Fig. 3 but for March 08, 2015

MSTIDs should be further studied. Of course, the inter-bubble distances will not necessarily coincide exactly with the horizontal wavelengths of the MSTIDs. If we assume that the EPB seeding occurs when the wave front intersects the solar terminator (Tsunoda 2015), which is moving to westward, the inter-bubble distance will depend on the horizontal wavelength, the phase velocity of the MSTID, and the westward movement of the solar terminator, as pointed out by Huang et al. (2013). In addition, the direction of propagation of the MSTID with respect to the local geomagnetic field lines is an important factor. If the wave propagation direction is perpendicular to the geomagnetic field (i.e., the wave front is parallel to the geomagnetic field), the effect of the F-layer uplifting should be large. Fritts et al. (2008) discussed favorable gravity wave orientations for the enhancement of the EPB seeding process. Therefore, the 
longitudinal component of the horizontal wavelength could be another important factor controlling the inter-bubble distances. In our present study, however, we could not consider these factors because the wave characteristics in the equatorial to low latitude $\left(0-15^{\circ} \mathrm{S}\right)$ region could not be determined with sufficient accuracy. Instead, we used the dTEC maps obtained from the low to middle latitudes $\left(15-30^{\circ} \mathrm{S}\right)$ that presented MSTIDs propagating equatorward.

To study the relationship between the EPBs and the MSTIDs, all the EPB and MSTID occurrences observed in the $0-30^{\circ} \mathrm{S}$ region during the 2 years of 2014 and 2015 are shown in Fig. 8. In this figure, we plot the number of days of occurrences (monthly) of EPBs (blue bars) and MSTIDs (black line) and the same day occurrences of both EPBs and MSTIDs (red line). We considered it to be a "same day occurrence" when the MSTIDs occurred in the afternoon sector from 15:00 UT to 24:00 UT and the
EPBs started soon after the solar terminator passage between 21:00 UT and 24:00 UT. It is clear that the maximum occurrence of EPBs is during the period from September to March (blue bars). In the South American sector during austral summer, the solar terminator and geomagnetic field line align, which makes it favorable to a strong PRE condition resulting to the development of RTI and the generation of EPB, as explained by previous observations (e.g., Sobral et al. 2002; Nishioka et al. 2008). Conversely, the MSTID activity observed in the low to middle latitudes increased during the period from May to October (black line), which is opposite to the EPB occurrence. Therefore, the EPBs related to the MSTIDs occur primarily in March, April, September, and October, the equinox seasons, as shown by the red line. Note that, during the equinox season, the PRE amplitude normally remains high (Fejer 2011), which could provide favorable conditions for the development of RTIs.

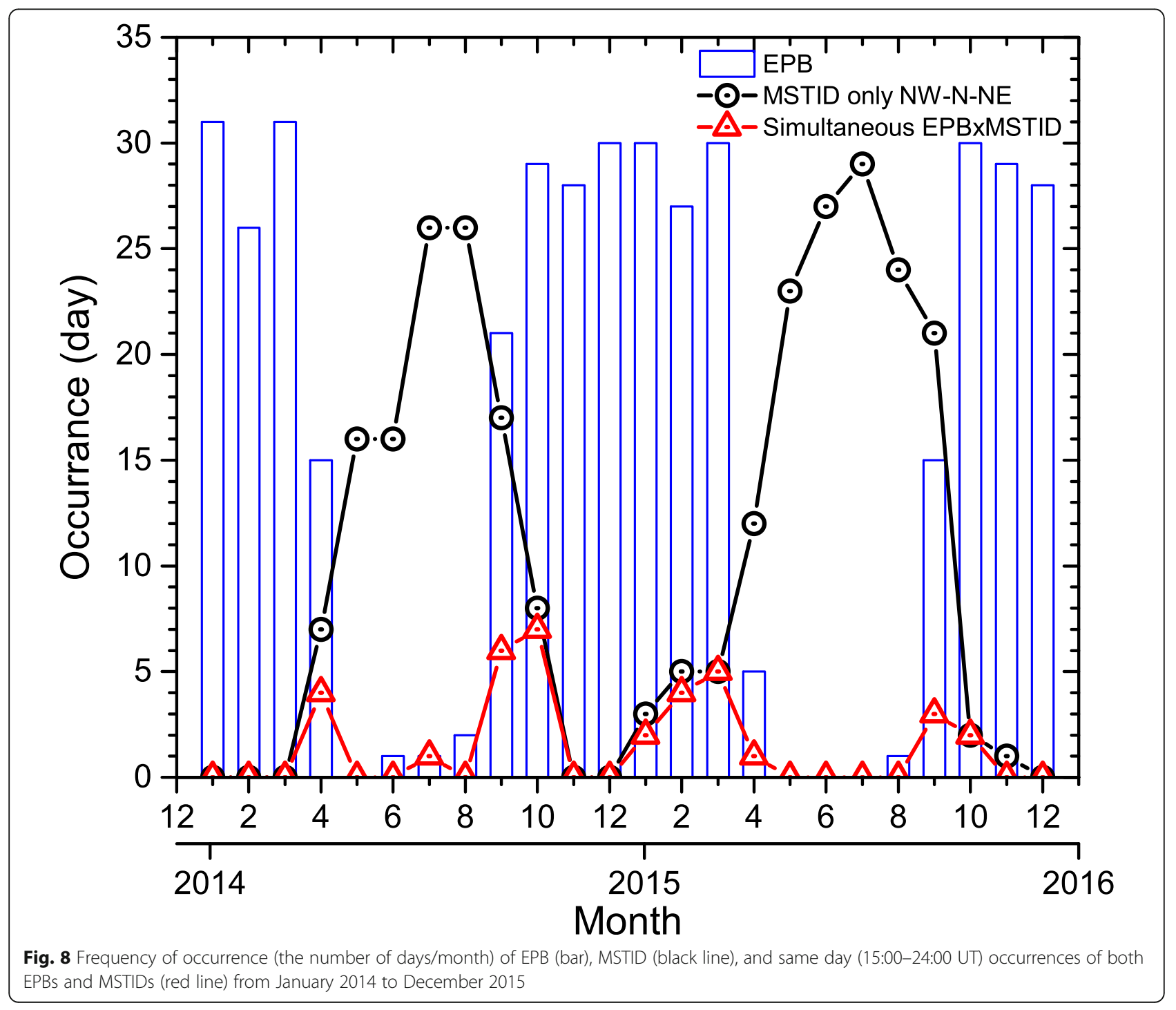


Figure 8 indicates that not all of the observed EPBs are related to MSTIDs. In the present study, therefore, we compared the EPB and MSTID characteristics in terms of the inter-bubble distance and the horizontal wavelength, respectively. We selected MSTIDs with propagation directions between $\mathrm{NW}\left(330^{\circ}\right)$ and $\mathrm{NE}\left(60^{\circ}\right)$. This is why the observed MSTIDs are primarily located at 20$30^{\circ} \mathrm{S}$, propagating equatorward and intersecting with the solar terminator. In addition, we limited the MSTID occurrence period from 15:00 UT (12:00 LT) to 24:00 UT (21:00 LT) and the EPB occurrence period to before 24:00 UT. In total, 35 cases of simultaneous MSTID and EPB occurrences were selected during the 2 years, which are presented in Fig. 9 (white circles). Each plot in Fig. 9 corresponds to a same day (15:00-24:00 UT) observation of an MSTID and EPB event. Both MSTIDs and EPBs have a range of variation between 300 and $1000 \mathrm{~km}$. Note that the two variables show a tendency to be linearly correlated with a correlation coefficient of 0.51 , suggesting an influence of the MSTIDs on the inter-distance of the EPBs. The plots are, however, rather scattered, indicating that some other factors need to be considered. This could be due to the relationship between the phase velocity with respect to the westward movement of the solar terminator and the longitudinal components of the MSTID horizontal wavelength, as mentioned earlier. A modulation in the MSTID phase velocity under the background wind field could also occur. However, the linear correlation between the two parameters suggests that MSTIDs are related to the inter-bubble distances.

Atmospheric gravity waves in the thermosphere (at an altitude of $150-250 \mathrm{~km}$ ) frequently come from below the mesopause region. A close relationship between mesospheric gravity waves (MGWs) and EPBs has been presented by Takahashi et al. (2009) and Paulino et al. (2011). They suggested the possibility of the upward propagation of MGWs into the bottom side of the $\mathrm{F}$ layer. In order to investigate the similarity between MGWs and MSTIDs versus EPBs, we also plotted in

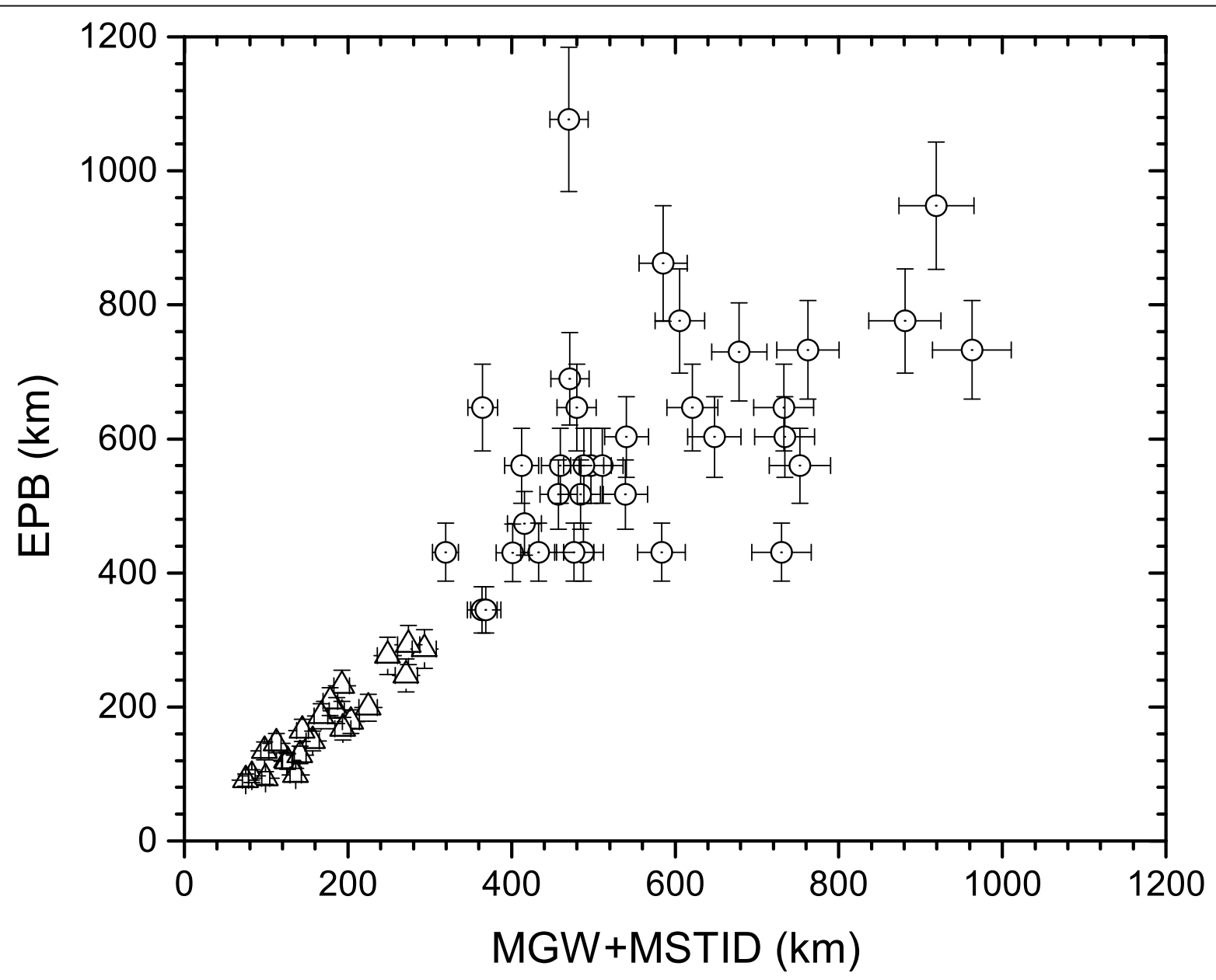

Fig. 9 Inter-bubble distances and same day observed horizontal wavelengths of the MSTIDs (black circles) and mesospheric gravity waves (MGWs) (triangles). Note that the group of MGWs was observed in 2012 


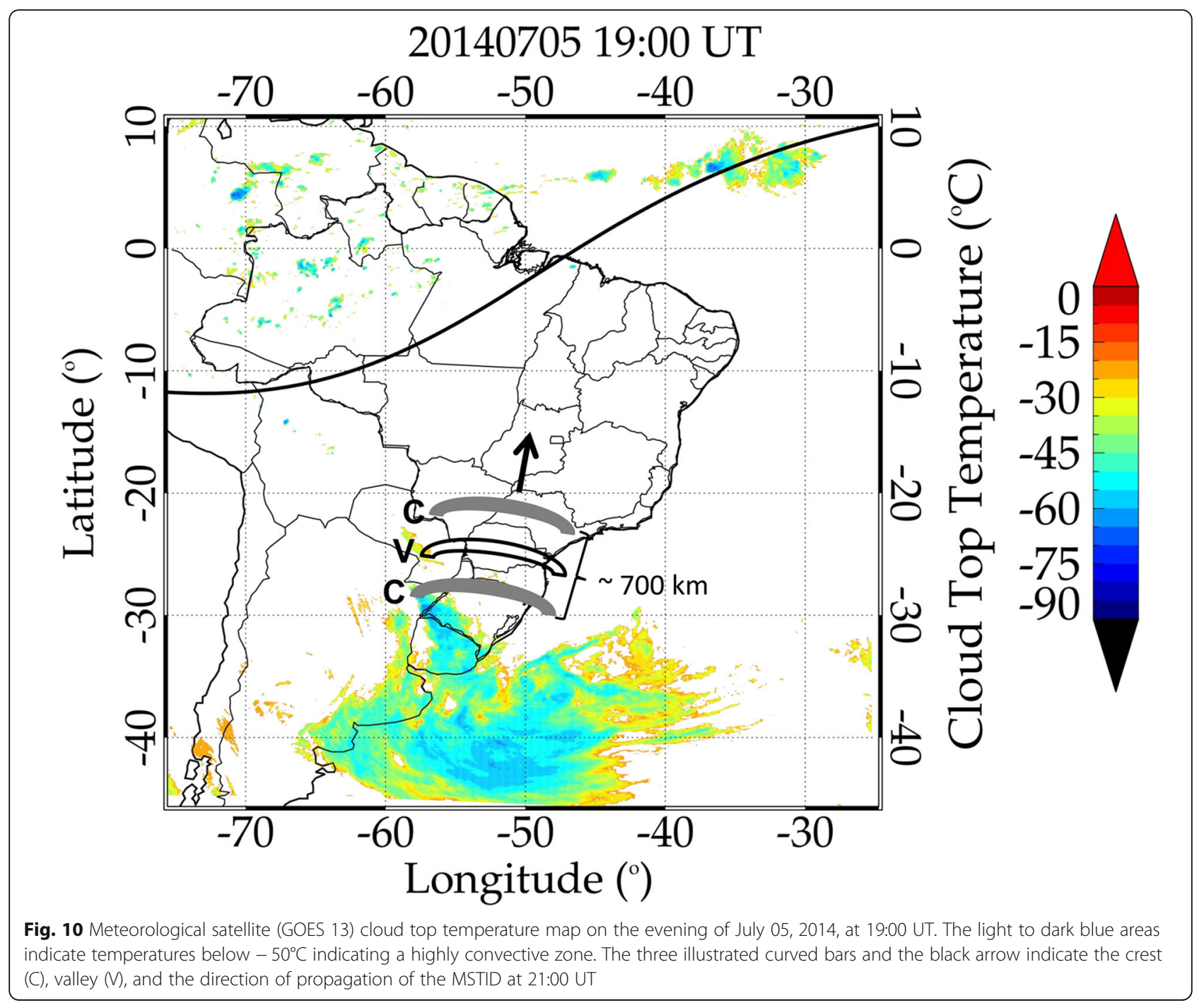

Fig. 9 the simultaneous occurrences of MGWs and EPBs (triangles) observed by the airglow imager at the Cariri airglow observatory $\left(7.4^{\circ} \mathrm{S}, 36.5^{\circ} \mathrm{W}\right)$ in 2012 . Note that, in this case, both MGWs and EPBs were observed simultaneously by the $\mathrm{OH}$ and $630 \mathrm{~nm}$ images, respectively, which is different from the case of the MSTIDs and EPBs. The simultaneous occurrences of MGWs and EPBs were observed on 22 evenings during the period of 2012, and their horizontal scale range was between 50 and $300 \mathrm{~km}$. Due to the limitation of the field of view of the imager $(\sim 800 \mathrm{~km})$, the observed horizontal wavelength was limited to less than $400 \mathrm{~km}$. A very clear linear relationship between EPB and MGW can be seen. Therefore, the two groups, one in the mesosphere (MGW) and the other in the ionosphere (MSTID), show a linear relationship with respect to EPB. This observational evidence implies that some of the EPBs are seeded by atmospheric perturbations generated by atmospheric gravity waves. Atmospheric gravity waves induce disturbances in the wind fields in the mesosphere and lower thermosphere, provoking up and down movements on the bottom side of the F layer. When the wave structure of the F-layer bottom side meets with the evening F-layer uplifting (due to the pre-reversal enhancement of the zonal electric field), it induces favorable conditions for RTIs and producing EPBs. Therefore, the horizontal wavelength of the wave structure causes the periodic generation of EPBs. Tsunoda (2010) and Tsunoda et al. (2011) have proposed the existence of large-scale wave structures (LSWSs) to explain the periodic structure of the EPBs along geomagnetic longitudes. Our present results agree with their hypothesis and support it with observational evidence.

The better correlation of EPB and MGW compared to EPB and MSTID suggests that MGWs might cause a direct modulation of the F-layer bottom heights and that this happens nearly simultaneously in the same region. Conversely, MSTIDs might act to modulate the F layer 


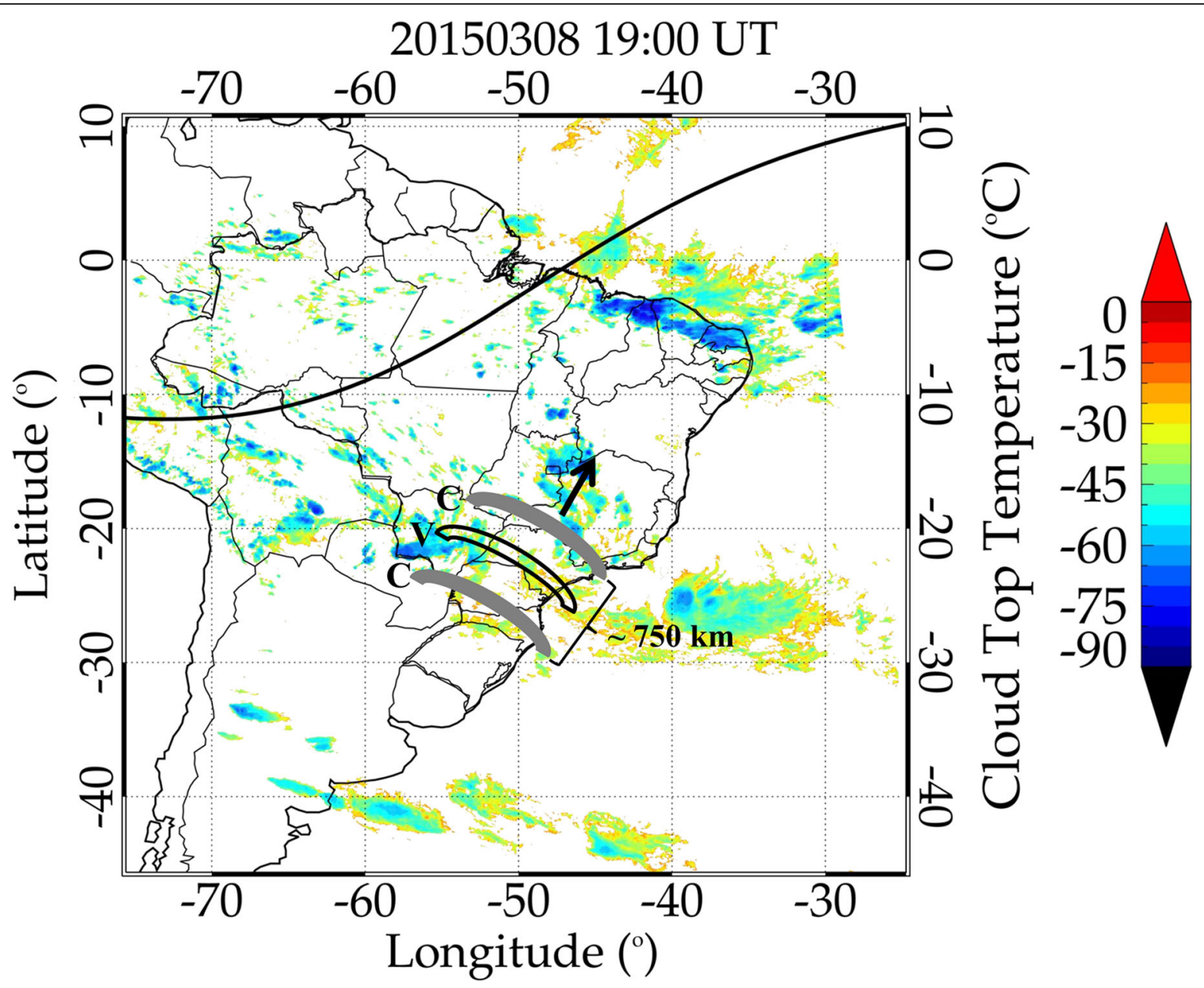

Fig. 11 Meteorological satellite (GOES 13) cloud top temperature map: same as Fig. 10 but for March 08, 2015, at 19:00 UT. The three illustrated curved bars and the black arrow indicate the propagation of the MSTID at 22:30 UT

in different ways, as mentioned above. Note that EPB bifurcations could also produce the EPB periodic structure in the longitudinal plane. Bifurcations could occur under the plasma instability inside a large-scale $\mathrm{EPB}$, and the longitudinal distance between EPBs appears to be less than $100 \mathrm{~km}$ (Yokoyama et al. 2014). Therefore, the possible contribution of bifurcations cannot be ruled out.

\section{Seeding of MSTIDs}

An MSTID is a signature of an ionospheric disturbance that might have two origins. One possible origin is electrodynamical forces under the condition of the Perkins instability in the high to middle latitudes during the nighttime (Perkins 1973). Miller et al. (2009) and Yokoyama et al. (2011) have suggested that nighttime MSTIDs, accompanied by polarized electric fields, could propagate to low latitudes and cause Rayleigh-Taylor instabilities in the region of the geomagnetic equator near midnight.

The second origin could be neutral atmosphere gravity waves generated in the lower atmosphere (Vadas and
Crowley 2010). It is well known that large-scale cloud convection generates upwards propagating atmospheric gravity waves (GWs) (Vadas 2007). A part of the GWs could propagate upwards reaching the lower thermosphere. For example, gravity waves with horizontal wavelengths of 400-600 km can propagate above $220 \mathrm{~km}$ before dissipating (Vadas 2007). In order to search for the origins of tropospheric gravity waves, tropospheric cloud convection activity monitored by the cloud top temperature observed by a meteorological satellite (GOES 13) are shown in Fig. 10 for case 1 on July 05, 2014, at 19:00 UT (CPTEC: http://satelite.cptec.in pe.br/home/index.jsp). The light to dark blue areas in the figure show a convection system with a temperature below $-50{ }^{\circ} \mathrm{C}$, indicating highly convective zones. There is a cold front extending from NW to SE in the south of Brazil. This area corresponds to where the MSTID was detected at $20-30^{\circ} \mathrm{S}$ in Fig. 4 . The identified wave front (crest and valley) at 21:00 UT is illustrated in Fig. 10. 
Regarding case 2, Fig. 11 shows the cloud top temperature on March 08, 2015, at 19:00 UT. There are two large convective systems, one on the northern coast of Brazil, which is the intertropical convergence zone (ITCZ), and the other is a cold front extending over the southeast of Brazil. If one compares this with the dTEC keogram in Fig. 6, it is clear that the observed MSTIDs, both from the equatorial (propagating southward) and the mid-latitude (propagating northward) regions, could be related to these tropospheric convection activities. One MSTID event observed at 22:30 UT is illustrated in Fig. 11. This observational evidence indicates that many MSTIDs likely have their origin in atmospheric gravity waves generated in tropospheric convections and the ITCZ. However, it is difficult to identify in the present work which convection system caused which MSTID. To further investigate the coupling process from the troposphere to the thermosphere-ionosphere, simulations of GW ray tracing are necessary.

\section{Conclusions}

Occurrences of equatorial plasma bubbles (EPBs) and medium-scale traveling ionospheric disturbances (MSTIDs) in the afternoon to evening period were studied using ionospheric TEC, dTEC, ionograms, and $630 \mathrm{~nm}$ airglow images. Occasionally (July 05, 2014), EPBs were observed without conditions favorable for F-layer uplifting but in the presence of MSTIDs. Another specific case was March 08, 2015, when we observed strong convective activities in the troposphere and MSTID and EPB activities in the evening. In both cases, the inter-bubble distances were similar to the horizontal wavelengths of the MSTIDs. In 2 years of data (2014-2015), 35 cases showed same day occurrences of MSTIDs and EPBs. The inter-bubble distances were similar to the horizontal wavelengths of the MSTIDs. Horizontal wavelengths of the mesospheric gravity waves observed in 2012 were also correlated to simultaneously observed EPBs. Based on the observational evidence, we conclude that MSTIDs could be one of the EPB seeding processes.

\begin{abstract}
Abbreviations
dSTEC: Temporal perturbation of the line-of-sight total electron content; dTEC: Temporal perturbation of the total electron content from the average; EMBRACE: Brazilian Studies and Monitoring of Space Weather; EPBs: Equatorial plasma bubbles; GNSS: Global navigation satellite system; GPS: Global positioning system; GWs: Gravity waves; hF: F-layer true height; ITCZ: Intertropical convergence zone; LSWS: Large-scale wave structure; LT: Local (standard) time; MGWs: Mesospheric gravity waves; MSTID: Medium-scale traveling ionospheric disturbance; PRE: Pre-reversal enhancement of the electric field; PS-EIA: Post-sunset equatorial ionization anomaly; RTI: Rayleigh-Taylor instability; STEC: Line-of-sight total electron content; TEC: Total electron content; TECMap: Total electron content map; UT: Universal time; VTEC: Vertical total electron content
\end{abstract}

\section{Acknowledgements}

The TEC, ionogram, and imager data used in the present work are available at EMBRACE website. The GNSS ground-based receiver data were collected from the different GNSS networks in South America: RBMC (Rede Brasileiro de Monitoramento Continuo) of IBGE (Instituto Brasileiro de Geografia e Estatistica),
RAMSAC (Red Argentina de Monitoreo Satelital Continuo) from Argentina, and IGS (International GNSS Service) and LISN (Low-Latitude Ionospheric Sensor Network) of Boston College. We are grateful to these network sites for providing the data continuously. The cloud top temperature maps were provided by the Center for Weather Forecasting and Climate Studies (CPTEC/INPE). This work was carried out by the joint research program of the Institute for Space-Earth Environmental Research (ISEE), Nagoya University. H. Takahashi thanks ISEE, Nagoya University, for supporting to develop the present work during the scientific visit in 2016.

\section{Funding}

K. Shiokawa and Y. Otsuka thank the support of JSPS (Japan Society for Promotion of Science) KAKENHI (grant JP 15H05815) to this work. The present work was also supported by CNPq (Conselho Nacional de Pesquisa e desenvolvimento) under the grant 30.5461/2015-0, 150569/ 2017-3, 161894/2015-1 and CAPES (Coordenação de Aperfeiçoamento de Pessoal de Nivel Superior), under the process BEX4488/14-8. HT was partly supported by CNPq grant 30.5461/2015-0.

\section{Authors' contributions}

All authors read and approved the final manuscript.

\section{Competing interests}

The authors declare that they have no competing interests.

\section{Publisher's Note}

Springer Nature remains neutral with regard to jurisdictional claims in published maps and institutional affiliations.

\section{Author details}

${ }^{1}$ Instituto Nacional de Pesquisas Espaciais, INPE, São José dos Campos, SP, Brazil. ${ }^{2}$ Institute for Space-Earth Environmental Research, ISEE, Nagoya University, Nagoya, Japan.

Received: 30 October 2017 Accepted: 12 May 2018

Published online: 11 June 2018

\section{References}

Abdu MA (2001) Outstanding problems in the equatorial ionospherethermosphere electrodynamics relevant to spread F. J Atmos Solar-Terr Phys 63:869-884 PII: S1364-6826(00)00201-7.

Abdu MA (2005) Equatorial ionosphere-thermosphere system: electrodynamics and irregularities. Adv Space Res 35:771-787. https://doi.org/10.1016/j.asr. 2005.03.150.

Abdu MA, de Souza JR, Kherani EA, Batista IS, MacDougall JW, Sobral JHA (2015) Wave structure and polarization electric field development in the bottomside F layer leading to postsunset equatorial spread F. J Geophys Res Space Physics 120:6930-6940. https://doi.org/10.1002/2015JA021235.

Abdu MA, Kherani EA, Batista IS, de Paula ER, Fritts DC, Sobral JHA (2009) Gravity wave initiation of equatorial spread F/plasma bubble irregularities based on observational data from the SpreadFEx campaign. Ann Geophys 27:2607-2622.

Barros D, Takahashi H, Wrasse CM, Figueiredo CAOB (2018) Characteristics of equatorial plasma bubbles observed by TEC map based on ground-based GNSS receivers over South America. Ann Geophys 36:91-100 doi:org/10. 5194/angeo-36-91-2018.

Duly TM, Chapagain NP, Makela JJ (2013) Climatology of nighttime medium-scale traveling ionospheric disturbances (MSTIDs) in the Central Pacific and South American sectors. Ann Geophys 31:2229-2237, 2013. https://doi.org/10.5194/ angeo-31-2229-2013.

Fejer BG (2011) Low latitude ionospheric electrodynamics. Space Sci Rev 158: 145-166. https://doi.org/10.1007/s11214-010-9690-7.

Figueiredo CAOB, Takahashi H, Wrasse CM, Otsuka Y, Shiokawa K, Barros D (2018) Medium scale traveling ionospheric disturbances observed by detrended total electron content maps over Brazil. J Geophys Res: Space Phys 123. doi: https://doi.org/10.1002/2017JA025021.

Figueiredo CAOB, Wrasse CM, Takahashi H, Otsuka Y, Shiokawa K, Barros D (2017) Large-scale traveling ionospheric disturbances observed by GPS dTEC maps over North and South America on Saint Patrick's Day storm in 2015. J Geophys Res Space Physics 122:4755-4763. https://doi.org/10.1002/2016JA023417. 
Fritts DC, Vadas SL, Riggin DM, Abdu MA, Batista IS, Takahashi H, Medeiros A, Kamalabadi F, Liu H-L, Fejer BG, Taylor MJ (2008) Gravity wave and tidal influences on equatorial spread $F$ based on observations during the Spread $F$ Experiment (SpreadFEx). Ann Geophys 26:3235-3252. https://doi.org/10.5194/ angeo-26-3235-2008.

Fukushima D, Shiokawa K, Otsuka Y, Ogawa T (2012) Observation of equatorial nighttime medium-scale traveling ionospheric disturbances in 630-nm airglow images over 7 years. J Geophys Res 117:A10324. https://doi.org/10. 1029/2012JA017758.

Huang C-S, La BeaujardièRe O, Roddy PA, Hunton DE, Ballenthin JO, Hairston MR, Pfaff RF (2013) Large-scale quasiperiodic plasma bubbles: C/NOFS observations and causal mechanism. J Geophys Res, Space Phys 118(6):3602-3612 DOI:10. 1002/jgra.50338

Hunsucker RD (1982) Atmospheric gravity waves generated in the highlatitude ionosphere: a review. Rev Geophys 20(2):293-315 ISSN 19449208. 1, 5, 127, 129.

Kelley MC (2009) The earth's ionosphere: plasma physics and electrodynamics, International geophysics series 96. Academic press, San Diego.

Krall J, Huba JD, Ossakow SL, Joyce G, Makela JJ, Miller ES, Kelley MC (2011) Modeling of equatorial plasma bubbles triggered by non-equatorial traveling ionospheric disturbances. Geophys Res Letts 38:L08103. https://doi.org/10. 1029/2011GL046890.

Kudeki E, Akgiray A, Milla M, Chau JL, David L, Hysell DL (2007) Equatorial spreadF initiation: post-sunset vortex, thermospheric winds, gravity waves. J Atmos Solar-Terres Phys 69:2416-2427. https://doi.org/10.1016/j.jastp.2007.04.012.

Makela JJ, Vadas SL, Muryanto R, Duly T, Crowley G (2010) Periodic spacing between consecutive equatorial plasma bubbles. Geophys Res Lett 37: L14103. https://doi.org/10.1029/2010GL043968.

Miller E, Makela JJ, Kelley MC (2009) Seeding of equatorial plasma depletions by polarization electric fields from middle latitudes: experimental evidence. Geophys Res Lett 36:L18105. https://doi.org/10.1029/2009GL039695.

Nishioka M, Saito A, Tsugawa T (2008) Occurrence characteristics of plasma bubble derived from global ground-based GPS receiver networks. J Geophys Res 113:A05301. https://doi.org/10.1029/2007JA012605.

Otsuka Y, Shiokawa K, Ogawa T, Wilkinson P (2004) Geomagnetic conjugate observations of medium-scale traveling ionospheric disturbances at midlatitude using all-sky airglow imagers. Geophys Res Lett 31:L15803. https://doi.org/10.1029/2004GL020262.

Otsuka Y, Suzuki K, Nakagawa S, Nishioka M, Shiokawa K, Tsugawa T (2013) GPS observations of medium-scale traveling ionospheric disturbances over Europe. Ann Geophys 31:163-172. https://doi.org/10.5194/angeo-31163-2013.

Paulino I, Medeiros AF, Vadas SL, Wrasse CM, Takahashi H, Buriti RA, Leite D, Filgueira S, Bageston JV, Sobral JHA, Gobbi D (2016) Periodic waves in the lower thermosphere observed by $01630 \mathrm{~nm}$ airglow images. Ann Geophys 34:293-301 doi.org/10.5194/angeo-34-293-2016

Paulino I, Moraes JF, Maranhão GL, Wrasse CM, Buriti RA, Medeiros AF, Paulino AR, Takahashi H, Makela JJ, Meriwether JW, Campos JAV (2018) Intrinsic parameters of periodic waves observed in the O16300 airglow layer over the Brazilian equatorial region. Ann Geophys 36:265-273 doi.org/10.5194/angeo36-265-2018.

Paulino I, Takahashi H, Medeiros AF, Wrasse CM, Buriti RA, Sobral JHA, Gobbi D (2011) Mesospheric gravity waves and ionospheric plasma bubbles observed during the COPEX campaign. J Atmos Solar-Terr Phys 73:1575-1580. https:// doi.org/10.1016/j.jastp.2010.12.004.

Perkins F (1973) Spread F and ionospheric currents. J Geophys Res 78(1):218-226.

Rottger J (1973) Wave-like structures of large-scale equatorial spread-F irregularities. J Atmos Terr Phys 35:1195-1206.

Shiokawa K, Otsuka Y, Tsugawa T, Ogawa T, Saito A, Ohshima K, Kubota M, Maruyama T, Nakamura T, Yamamoto M, Wilkinson P (2005) Geomagnetic conjugate observation of nighttime medium-scale and large-scale traveling ionospheric disturbances: FRONT3 campaign. J Geophys Res 110(A05303). https://doi.org/10.1029/2004JA010845.

Singh S, Johnson FS, Power RA (1997) Gravity wave seeding of equatorial plasma bubbles. J Geophys Res 102(A4):7399-7410 doi: 0148-0227/97/96JA03998509.00

Sobral JHA, Abdu MA, Takahashi H, Taylor MJ, dePaula ER, Zamlutti CJ, deAquino MG, Borba GL (2002) lonospheric plasma bubble climatology over Brazil based on 22 years (1977-1998) of $630 \mathrm{~nm}$ airglow observations. J Atmos Solar-Terr Phys 64:1517-1524. https://doi.org/10.1016/S1364-6826(02)00089-5.
Takahashi H, Taylor MJ, Pautet P-D, Medeiros AF, Gobbi D, Wrasse CM, Fechine J, Abdu MA, Batista IS, de Paula E, Sobral JHA, Arruda D, Vadas SL, Sabbas FS, Fritts DC (2009) Simultaneous observation of ionospheric plasma bubbles and mesospheric gravity waves during the SpreadFEx Campaign. Ann Geophys 27:1477-1487. https://doi.org/10.5194/angeo-27-1477.

Takahashi H, Wrasse CM, Denardini CM, Pádua MB, de Paula ER, Costa SMA, Otsuka Y, Shiokawa K, Monico JFG, Ivo A, Sant'Anna N (2016) lonospheric TEC weather map over South America. Space Weather 14:937-949. https://doi. org/10.1002/2016SW001474.

Takahashi H, Wrasse CM, Otsuka Y, Ivo A, Gomes V, Paulino I, Medeiros AF, Denardini CM, Sant'Anna N, Shiokawa K (2015) Plasma bubble monitoring by TECmap and 630nm airglow image. J Atmos Solar Terr Phys 130-131:151158. https://doi.org/10.1016/j.jastp.2015.06.003.

Taori A, Parihar N, Ghodpage R, Dashora N, Sripathi S, Kherani EA, Patil PT (2015) Probing the possible trigger mechanisms of an equatorial plasma bubble event based on multistation optical data. J Geophys Res Space Phys 120. https://doi.org/10.1002/2015JA021541.

Tsunoda RT (2010) On seeding equatorial spread F: circular gravity waves. Geophys Res Lett 37:L10104. https://doi.org/10.1029/2010GL043422.

Tsunoda RT (2015) Upwelling: a unit of disturbance in equatorial spread F. Prog Earth Planet Sci 2:9. https://doi.org/10.1186/s40645-015-0038-5.

Tsunoda RT, Yamamoto M, Tsugawa T, Hoang TL, Tulasi Ram S, Thampi SV, Chau HD, Nagatsuma T (2011) On seeding large-scale wave structure equatorial spread F and scintillations over Vietnam. Geophys Res Lett 38:L20102. https:// doi.org/10.1029/2011GL049173.

Tulasi Ram S, Yamamoto M, Tsunoda RT, Chau HD, Hoang TL, Damtie B, Wassaie M, Yatini CY, Manik T, Tsugawa T (2014) Characteristics of large-scale wave structure observed from African and Southeast Asian longitudinal sectors. J Geophys Res Space Physics 119(3)3: 2288-2297. doi:https://doi.org/10.1002/ 2013JA019712

Vadas S (2007) Horizontal and vertical propagation and dissipation of gravity waves in the thermosphere from lower atmospheric and thermospheric sources. J Geophys Res 112:A06305. https://doi.org/10.1029/2006JA011845.

Vadas S, Crowley G (2010) Sources of the traveling ionospheric disturbances observed by the ionospheric TIDDBIT sounder near Wallops Island on 30 October 2007. J Geophys Res 115:A07324. https://doi.org/10.1029/ 2009JA015053.

Yokoyama T, Shinagawa H, Jin H (2014) Nonlinear growth, bifurcation and pinching of equatorial plasma bubble simulated by three-dimensional highresolution bubble model. J Geophys Res Space Physics 119:10,474-10,482. https://doi.org/10.1002/2014JA020708.

Yokoyama T, Yamamoto M, Otsuka Y, Nishioka M, Tsugawa T, Watanabe S, Pfaff RF (2011) On postmidnight low-latitude ionospheric irregularities during solar minimum: 1. Equatorial Atmosphere Radar and GPS-TEC observations in Indonesia. J Geophys Res 116:A11325. https://doi.org/10.1029/2011JA016797.

\section{Submit your manuscript to a SpringerOpen ${ }^{\circ}$ journal and benefit from:}

- Convenient online submission

- Rigorous peer review

- Open access: articles freely available online

- High visibility within the field

- Retaining the copyright to your article

Submit your next manuscript at $>$ springeropen.com 